\title{
Ceftolozane-Tazobactam in the Treatment of Experimental Pseudomonas aeruginosa Pneumonia in Persistently Neutropenic Rabbits: Impact on Strains with Genetically Defined Mechanisms of Resistance
}

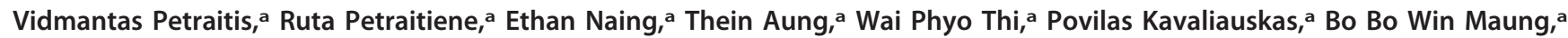 \\ Adam O. Michel, ${ }^{b}$ Rodolfo J. Ricart Arbona, ${ }^{c}$ Andrew C. DeRyke, ${ }^{d}$ Darren L. Culshaw, ${ }^{d}$ David P. Nicolau, ${ }^{e}$ Michael J. Satlin, ${ }^{a}$ \\ Thomas J. Walsha,f,g \\ aTransplantation-Oncology Infectious Diseases Program, Division of Infectious Diseases, Department of Medicine, Weill Cornell Medicine of Cornell University, New York,
New York, USA \\ bLaboratory of Comparative Pathology, Center of Comparative Medicine and Pathology, Memorial Sloan Kettering Cancer Center, The Rockefeller University, Weill \\ Cornell Medicine, New York, New York, USA \\ 'Center for Comparative Medicine and Pathology, Memorial Sloan Kettering Cancer Center and Weill Cornell Medicine, New York, New York, USA \\ dMerck and Co., Inc., Kenilworth, New Jersey, USA \\ eCenter for Anti-Infective Research and Development, Hartford Hospital, Hartford, Connecticut, USA \\ fDepartment of Pediatrics, Weill Cornell Medicine, New York, New York, USA \\ gDepartment of Microbiology and Immunology, Weill Cornell Medicine, New York, New York, USA
}

ABSTRACT Ceftolozane-tazobactam (C/T) is a novel cephalosporin with in vitro activity against Pseudomonas aeruginosa that is resistant to extended-spectrum penicillins and antipseudomonal cephalosporins. In order to assess the antimicrobial effect of $\mathrm{C} / \mathrm{T}$ in treatment of Pseudomonas pneumonia, we investigated the pharmacokinetics and efficacy of $\mathrm{C} / \mathrm{T}$ in persistently neutropenic rabbits. Pseudomonas pneumonia was established by direct endotracheal inoculation. Treatment groups consisted of $C / T$, ceftazidime (CAZ), piperacillin-tazobactam (TZP), and untreated controls (UC). Rabbits received a dosage of $\mathrm{C} / \mathrm{T}$ of $80 \mathrm{mg} / \mathrm{kg}$ every $4 \mathrm{~h}$ (q4h) intravenously (i.v.) (53 mg/kg ceftolozane $/ 26 \mathrm{mg} / \mathrm{kg}$ tazobactam) to match the free drug time above the MIC as well as a comparable plasma area under the concentration-time curve (AUC) (humanized doses of ceftolozane-tazobactam of $3 \mathrm{~g}[2 \mathrm{~g} / 1 \mathrm{~g}]$ ) q8h, due to the more rapid elimination of ceftolozane in rabbits $(0.75 \mathrm{~h})$ than in humans $(2.5 \mathrm{~h})$. Four molecularly characterized clinical $P$. aeruginosa isolates from patients with pneumonia were studied, including one isolate from each classification group: pan-susceptible (PS), outer membrane porin D (OPRD) porin loss (OPRDPL), efflux pump expression (EPE), and AmpC hyperexpression (ACHE). Treatment was continued for 12 days. Treatment with ceftolozane-tazobactam resulted in $a \geq 10^{5}$ reduction in residual pulmonary and bronchoalveolar lavage (BAL) fluid bacterial burdens caused by all 4 strains $(P \leq 0.01)$. This antibacterial activity coincided with reduction of lung weight (an organism-mediated pulmonary injury marker) $(P<0.05)$. CAZ was less active in ACHE-infected rabbits, and TZP had less activity against EPE, ACHE, and OPRDPL strains. Survival was prolonged in the $C / T$ and $C A Z$ treatment groups in comparison to the TZP and UC groups $(P<0.001)$. Ceftolozane-tazobactam is highly active in treatment of experimental $P$. aeruginosa pneumonia in persistently neutropenic rabbits, including infections caused by strains with the most common resistance mechanisms.

KEYWORDS Pseudomonas aeruginosa, ceftolozane-tazobactam, pneumonia, rabbits
Citation Petraitis $V$, Petraitiene R, Naing E, Aung T, Thi WP, Kavaliauskas P, Win Maung BB Michel AO, Ricart Arbona RJ, DeRyke AC Culshaw DL, Nicolau DP, Satlin MJ, Walsh TJ. 2019. Ceftolozane-tazobactam in the treatment of experimental Pseudomonas aeruginosa pneumonia in persistently neutropenic rabbits: impact on strains with genetically defined mechanisms of resistance. Antimicrob Agents Chemother 63:e00344-19. https://doi.org/10.1128/AAC.00344-19. Copyright $\odot 2019$ American Society for Microbiology. All Rights Reserved. Address correspondence to Vidmantas Petraitis, vip2007@med.cornell.edu. Received 21 February 2019 Returned for modification 14 March 2019 Accepted 13 June 2019

Accepted manuscript posted online 24 June 2019

Published 23 August 2019 
seudomonas aeruginosa pneumonia is a life-threatening infection with high mortality, particularly in neutropenic patients (1-4). The efficacy of current antimicrobial therapy with extended-spectrum penicillins (ESPs) and antipseudomonal cephalosporins (ASCs) is limited by intrinsic resistance or by emergence of resistant isolates during therapy (4-6). Ceftolozane-tazobactam $(C / T)$ is a novel cephalosporin with in vitro activity against the majority of isolates of $P$. aeruginosa that are resistant to ESPs and ASCs $(5,7,8)$. However, data characterizing the in vivo activity of $C / T$ against these highly resistant strains are limited. $\mathrm{C} / \mathrm{T}$ is currently indicated for complicated intraabdominal infections, used in combination with metronidazole, and for complicated urinary tract infections, including pyelonephritis (9). A major clinical trial of ceftolozanetazobactam for treatment of hospital-acquired pneumonia and ventilator-associated pneumonia has been recently completed (10).

A comprehensive understanding of the pharmacokinetics and efficacy of $C / T$ in experimental Pseudomonas pneumonia in an in vivo model that simulates profoundly immunocompromised oncology patients is necessary for optimizing therapeutic outcome in this serious infection. In order to establish the correct bridging of exposures between rabbit and human dosages and to assess the antimicrobial effect of ceftolozane-tazobactam in treatment of Pseudomonas pneumonia, we investigated this new agent in the treatment of experimental $P$. aeruginosa pneumonia in persistently neutropenic rabbits infected with different strains with genetically defined mechanisms of resistance.

\section{RESULTS}

Multidose plasma pharmacokinetics. As the result of the faster clearance of ceftolozane in rabbits than humans, the plasma pharmacokinetics of ceftolozanetazobactam in this study were determined in normal rabbits in order to define a humanized dosing. The modeling was accomplished based upon $f T>$ MIC and area under the concentration-time curve (AUC). Such studies had not been previously performed for ceftolozane-tazobactam in rabbits. The exposures of ceftolozane simulated that of the $3-\mathrm{g}$ dose that has been used in the adult study for bacterial pneumonia. The area under the concentration-time curve from 0 to $8 \mathrm{~h}\left(\mathrm{AUC}_{\mathrm{O}-8}\right)$ of ceftolozane on day 6 after intravenous (i.v.) administration of ceftolozane-tazobactam at 40,80 , and $160 \mathrm{mg} / \mathrm{kg}$ every $8 \mathrm{~h}$ (q8h) to healthy New Zealand White rabbits ranged from $155.87 \pm 15.02$ to $494.06 \pm 14.00 \mu \mathrm{g} \cdot \mathrm{h} / \mathrm{ml}$ (Fig. 1; Table 1). The exposure of $375.83 \pm 23.84 \mu \mathrm{g} \cdot \mathrm{h} / \mathrm{ml}$ achieved by $80 \mathrm{mg} / \mathrm{kg}(53 \mathrm{mg} / \mathrm{kg} / 26 \mathrm{mg} / \mathrm{kg})$ ceftolozanetazobactam was comparable to that of the adult human dose of $2 \mathrm{~g}$ ceftolozane $/ 1 \mathrm{~g}$ tazobactam (8), and thus this dosage was selected for the therapeutic portion of the study. A strong correlation was observed between AUCs and dosages ( $r=0.9136$; $P=0.0001$ ) (Fig. 2). The mean epithelial lining fluid (ELF) concentration of ceftolozane in $8 \mathrm{immunocompetent} \mathrm{noninfected} \mathrm{rabbits} \mathrm{was} 10.6 \pm 2.7 \mu \mathrm{g} / \mathrm{ml}$. The median serum protein binding measured by equilibrium dialysis for ceftolozane was $12 \%$. The estimated free drug exposure of ceftolozane achieved by $80 \mathrm{mg} / \mathrm{kg}(53 \mathrm{mg} / \mathrm{kg} / 26 \mathrm{mg} / \mathrm{kg})$ ceftolozane-tazobactam is $331 \mu \mathrm{g} \cdot \mathrm{h} / \mathrm{ml}$, and the fAUC/MIC ranged from $662 \mu \mathrm{g}$. $\mathrm{h} / \mathrm{ml} /(\mu \mathrm{g} / \mathrm{ml})$ for the wild type to $83 \mu \mathrm{g} \cdot \mathrm{h} / \mathrm{ml} /(\mu \mathrm{g} / \mathrm{ml})$ for the efflux pump-expressing isolate. For the plasma concentration-time curve of ceftolozane dosed at $80 \mathrm{mg} / \mathrm{kg}$, the minimum concentration $\left(C_{\text {min }}\right.$ ) was approximately $10 \mu \mathrm{g} / \mathrm{ml}$ (Fig. 1). With 12\% rabbit protein binding, an $f C_{\min }$ of 8 to $9 \mu \mathrm{g} / \mathrm{ml}$ was achieved. With the highest MIC tested against ceftolozane-tazobactam being $4 \mu \mathrm{g} / \mathrm{ml}$, ceftolozane still remained $100 \%$ fT $>$ MIC in plasma.

Antibacterial treatment. Ceftolozane-tazobactam was highly effective in treating $P$. aeruginosa pneumonia caused by four strains with molecularly defined mechanisms of resistance (wild-type pan-susceptible, outer membrane porin D porin loss, efflux pump expression, and AmpC hyperexpression), as measured by significant reductions in residual pulmonary bacterial burden (CFU/g), residual bacterial burden in bronchoalveolar lavage (BAL) fluid, lung weights (markers of organism-mediated pulmonary injury), and survival. 


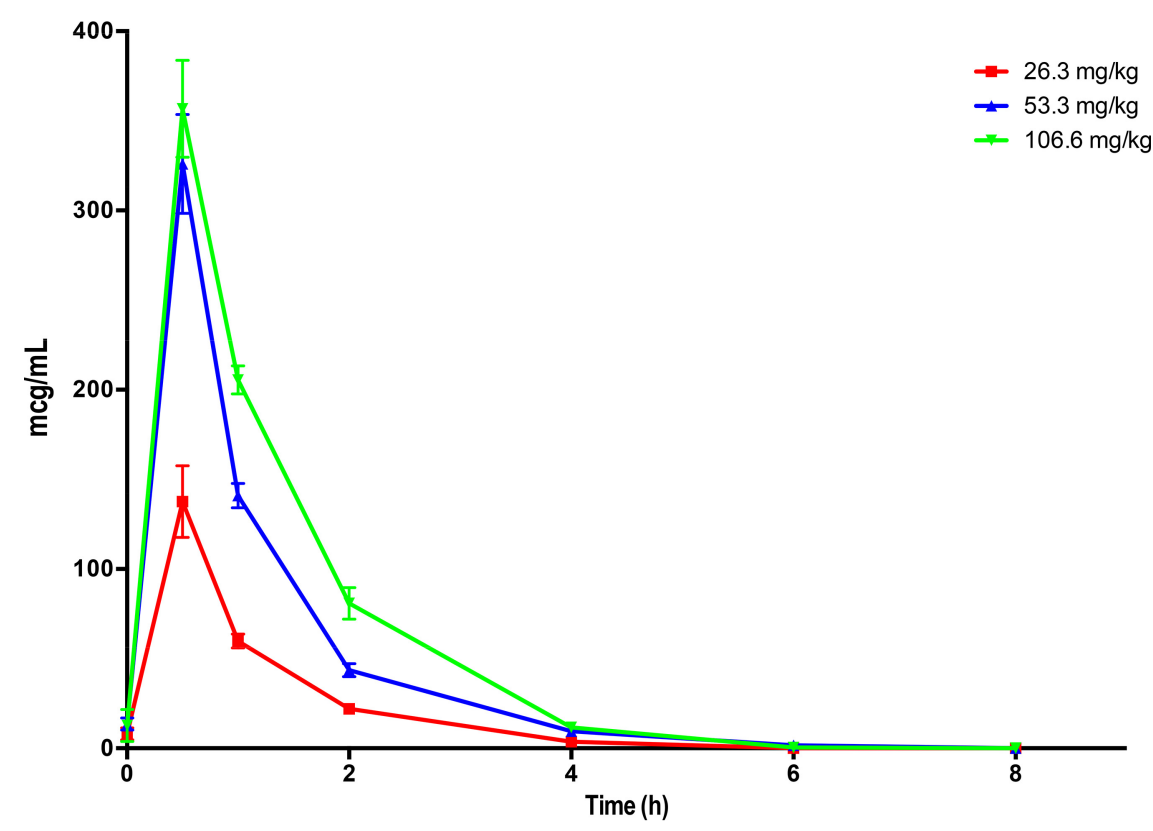

FIG 1 Plasma pharmacokinetics of ceftolozane on day 6 after intravenous administration of ceftolozanetazobactam at 40 ( $26.3 \mathrm{mg} / \mathrm{kg}$ ceftolozane), 80 (53.3 mg/kg ceftolozane), and 160 (106.6 mg/kg ceftolozane) $\mathrm{mg} / \mathrm{kg}$ every $8 \mathrm{~h}$ to healthy New Zealand White rabbits. All values are presented as means from samples of four animals each \pm SEM.

There were significant decreases in pulmonary bacterial burden in all treatment groups against the pan-susceptible (PS) strain in comparison to that of untreated controls (UC) $(P \leq 0.01)$. In addition, only $C / T$ - and CAZ-treated rabbits demonstrated significant decreases in bacterial burden in the lung tissue against outer membrane porin D (OPRD) porin loss (OPRDPL), efflux pump expression (EPE), and AmpC hyperexpression (ACHE) strains in comparison to those of UC $(P \leq 0.01)$ (Fig. 3). There were no significant decreases of bacterial burden in rabbits treated with TZP against OPRDPL, $E P E$, and $A C H E$ strains in comparison to that of UC. Full clearance of $P$. aeruginosa in the lungs was achieved in the $C / T$ treatment group against PS, OPRDPL, and EPE strains (Fig. 3). One should note that TZP and CAZ were used in this study as negative controls for treatment of molecularly defined resistant strains of $P$. aeruginosa such that a lack of response in vivo would be predicted. No direct comparison between $C / T$ and TXP or CAZ was intended or conducted.

These results correlated with significant decrease of bacterial burden in bronchoalveolar lavage (BAL) fluid in all treatment groups against PS and EPE strains in comparison to that of UC $(P \leq 0.05)$ (Fig. 4). On the other hand, only C/T- and CAZ-treated rabbits demonstrated a significant decrease of bacterial burden in BAL fluid against

TABLE 1 Plasma total drug pharmacokinetic parameters of ceftolozane-tazobactam on day 6 after intravenous administration of ceftolozane-tazobactam at 40,80 and $160 \mathrm{mg} / \mathrm{kg}$ every $8 \mathrm{~h}$ to healthy New Zealand White rabbits ${ }^{a}$

\begin{tabular}{|c|c|c|c|c|}
\hline Drug and dosage $(\mathrm{mg} / \mathrm{kg})$ & $\mathrm{AUC}_{(0-8)}(\mu \mathrm{g} \cdot \mathrm{h} / \mathrm{ml})$ & $C_{\max }(\mu \mathrm{g} / \mathrm{ml})$ & $\mathrm{CL}(\mathrm{ml} / \mathrm{h} / \mathrm{kg})$ & $V(\mathrm{ml} / \mathrm{kg})$ \\
\hline \multicolumn{5}{|l|}{ Ceftolozane } \\
\hline 53 & $375.83 \pm 23.84$ & $325.96 \pm 27.62$ & $142.13 \pm 9.01$ & $161.18 \pm 6.29$ \\
\hline \multicolumn{5}{|l|}{ Tazobactam } \\
\hline $13^{b}$ & $15.50 \pm 4.73$ & $20.77 \pm 8.16$ & $1,199.18 \pm 487.82$ & $248.35 \pm 65.07$ \\
\hline 26 & $30.09 \pm 4.82$ & $47.84 \pm 9.28$ & $929.57 \pm 127.33$ & $154.14 \pm 16.65$ \\
\hline
\end{tabular}

${ }^{a} \mathrm{CL}$, clearance; $\mathrm{V}$, volume of distribution. Values are means $\pm \mathrm{SEMs}$.

${ }^{b}$ Ceftolozane-tazobactam at $40 \mathrm{mg} / \mathrm{kg}=26.3 \mathrm{mg} / \mathrm{kg}$ ceftolozane and $13.6 \mathrm{mg} / \mathrm{kg}$ tazobactam. 


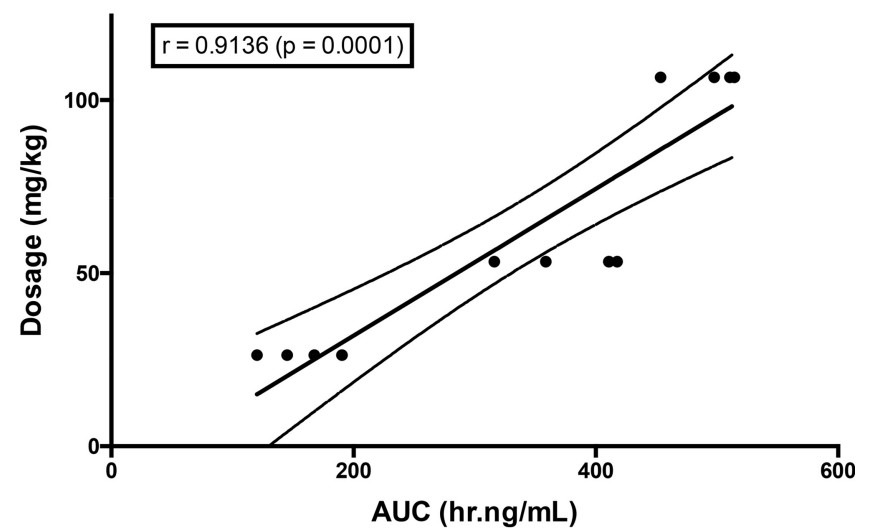

FIG 2 Dose proportionality of ceftolozane administered as ceftolozane-tazobactam across dosages of 26 and $106 \mathrm{mg} / \mathrm{kg}$ i.v.

OPRDPL $(P \leq 0.01)$ and ACHE $(P \leq 0.05$ for CAZ; $P \leq 0.01$ for $C / T)$ strains in comparison to that of UC (Fig. 4).

There were also significant decreases in total lung weights in rabbits treated with $\mathrm{C} / \mathrm{T}$ and $\mathrm{CAZ}$ against PS and OPRDPL strains in comparison to that of UC ( $P \leq 0.05$ ) (Fig. 4). Only $C / T$-treated rabbits demonstrated significant decreases in lung weights against

\section{Pan-Susceptible}

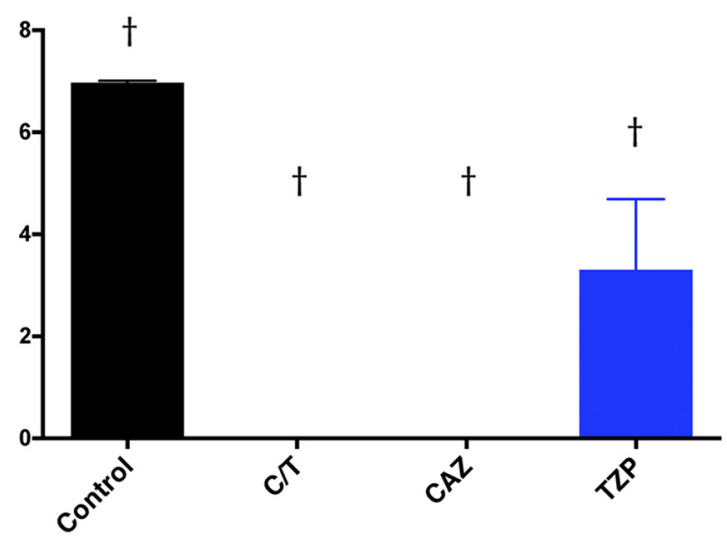

\section{Efflux pump expression}

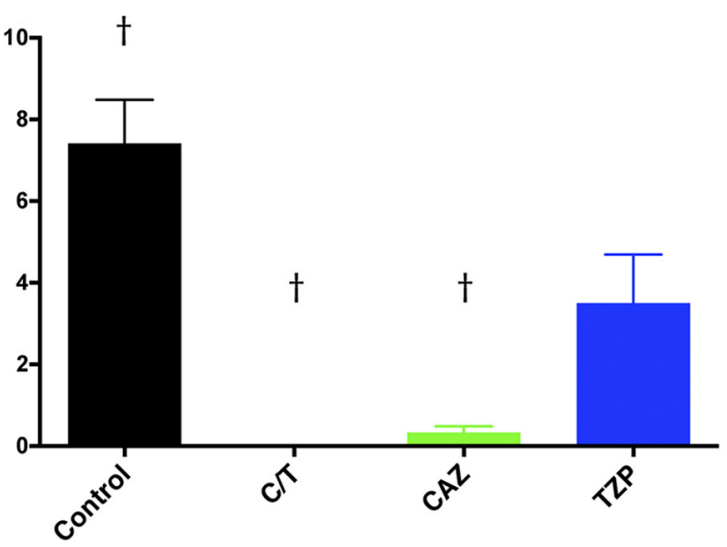

\section{OPRD porin loss}

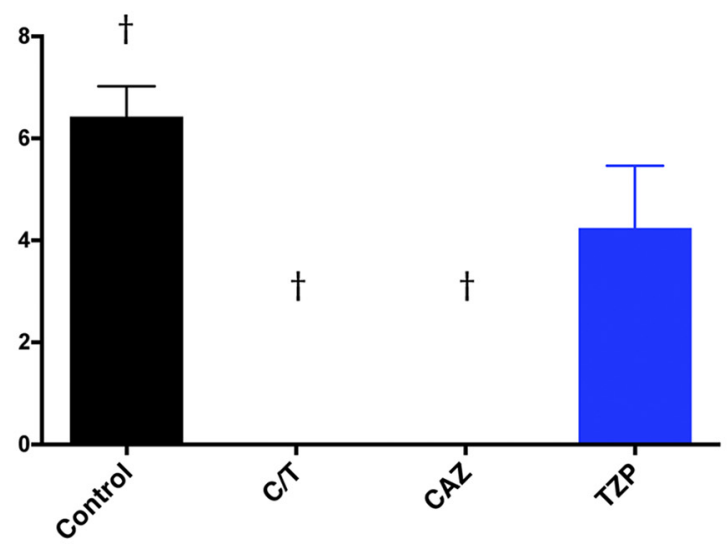

Amp C hyperexpression

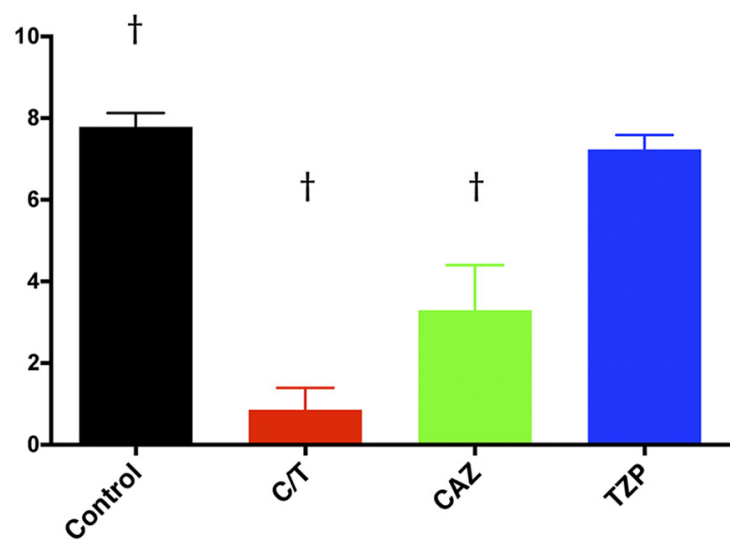

FIG 3 Pulmonary bacterial burden (log CFU/g) in rabbits with experimental Pseudomonas aeruginosa pneumonia treated with ceftolozanetazobactam (C/T), ceftazidime (CAZ), and piperacillin-tazobactam (TZP) according to mechanism of resistance. $\uparrow, P<0.01$ (decreased residual bacterial burden in treatment groups in comparison to that in untreated controls). All values are expressed as mean \pm SEM. 


\section{Pan-Susceptible}

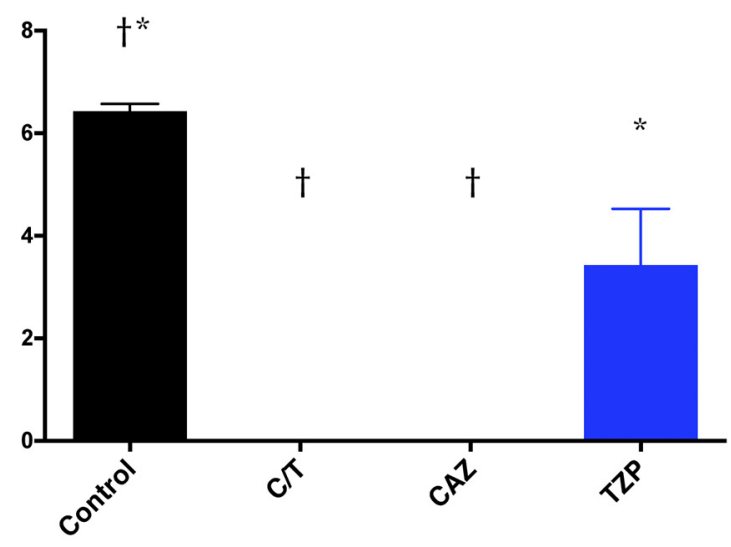

Efflux pump expression

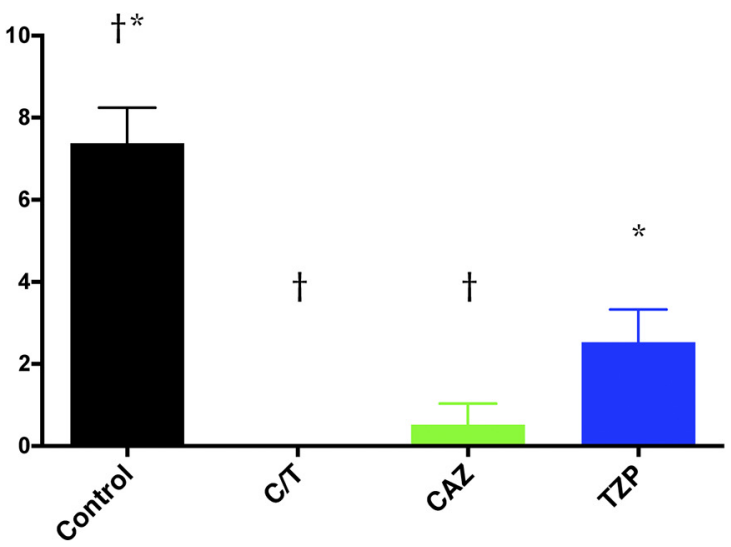

\section{OPRD porin loss}

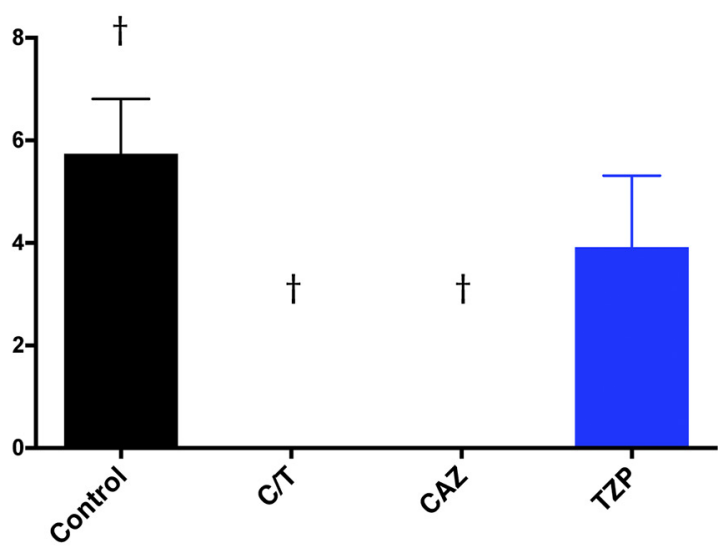

Amp C hyperexpression

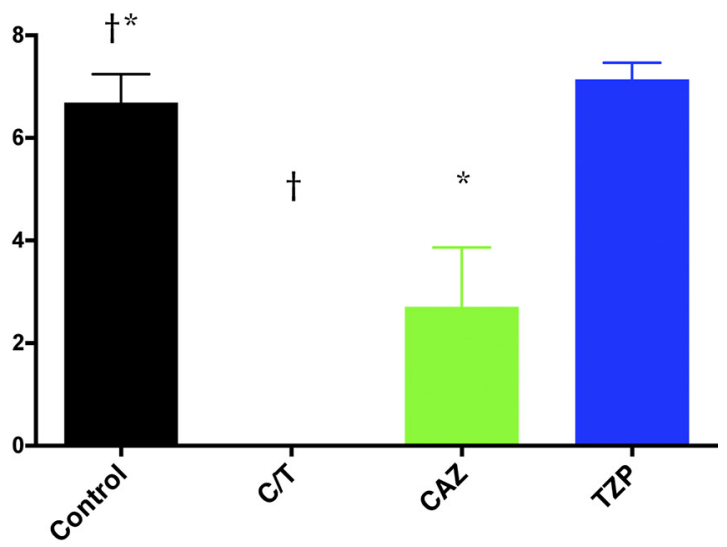

FIG 4 Bronchoalveolar lavage (BAL) fluid bacterial burden (log CFU/ml) in rabbits with experimental Pseudomonas aeruginosa pneumonia treated with ceftolozane-tazobactam (C/T), ceftazidime (CAZ), and piperacillin-tazobactam (TZP) according to mechanism of resistance. *, $P<0.05 ; \dagger, P<0.01$ (decreased residual bacterial burden in treatment groups in comparison to that in untreated controls). All values are expressed as mean \pm SEM.

EPE and ACHE strains $(P \leq 0.05)$. No obvious decrease in lung weights was observed in the TZP group against all strains in comparison to UC (Fig. 5).

Significantly prolonged survival was achieved in C/T $(P \leq 0.001)-$, CAZ $(P \leq 0.001)-$, and TZP $(P \leq 0.01)$-treated rabbits against the EPE strain in comparison to UC. The $C / T$ and CAZ study groups demonstrated significantly longer survival in treatment against PS and OPRDPL strains. In addition, rabbits treated with $C / T(P \leq 0.01)$ and $C A Z$ $(P \leq 0.05)$ against the ACHE strain demonstrated significantly prolonged survival in comparison to those treated with TZP and UC (Fig. 6).

\section{DISCUSSION}

This study demonstrated that ceftolozane-tazobactam was highly active in treatment of experimental $P$. aeruginosa pneumonia in persistently neutropenic rabbits when administered in humanized dosages simulating plasma exposures of $3 \mathrm{~g}$ q8h i.v. Ceftolozane-tazobactam also was effective in eradicating genetically distinct molecularly characterized strains of $P$. aeruginosa, including those encoding OPRDPL, EPE, and ACHE. Infections caused by all four isolates were effectively cleared from tissue, with excellent survival. These studies establish a preclinical foundation for primary treatment of $P$. aeruginosa pneumonia in persistently neutropenic patients.

Ceftolozane-tazobactam consists of a novel cephalosporin with a clinically proven $\beta$-lactam $\beta$-lactamase inhibitor $(4,11)$. Ceftolozane is an imino-isobutoxyaminothiazolyl cephalosporin, similar to ceftazidime, that differs structurally by substitution of the 
Pan-Susceptible

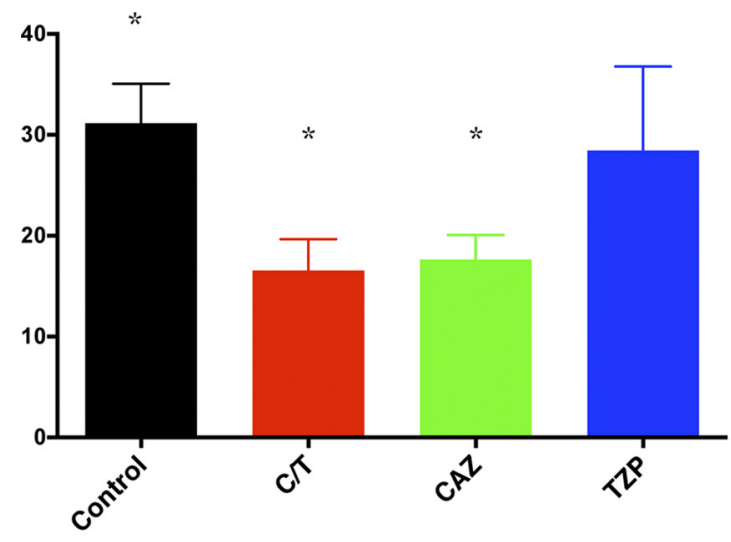

Efflux pump expression

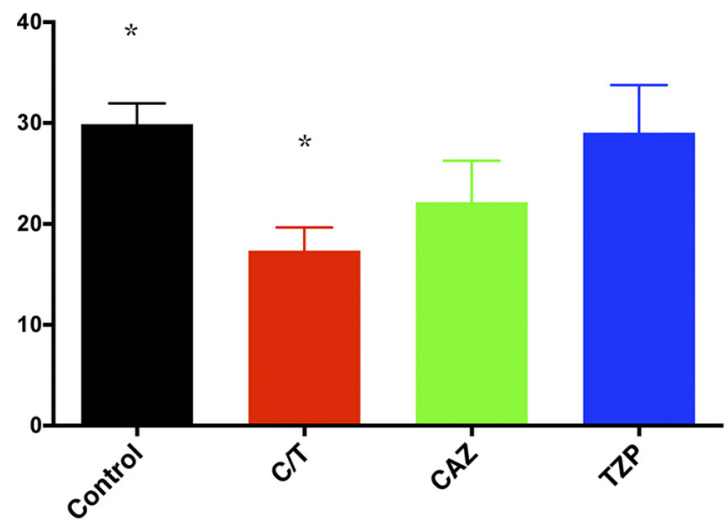

OPRD porin loss

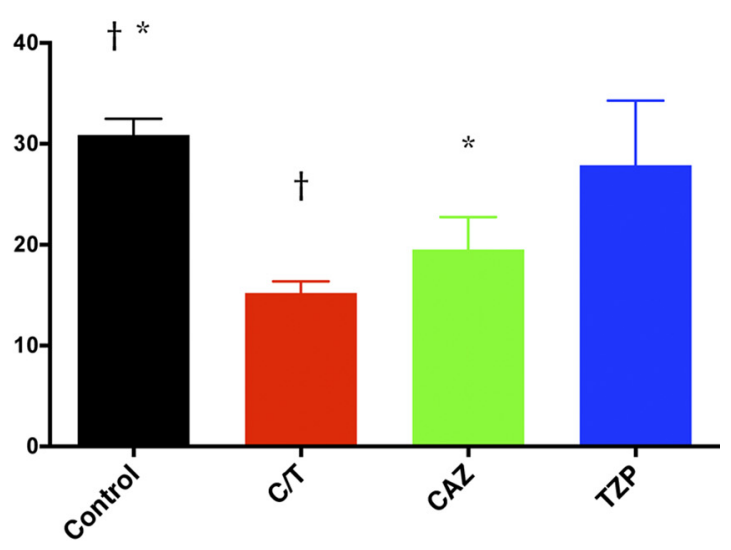

Amp C hyperexpression

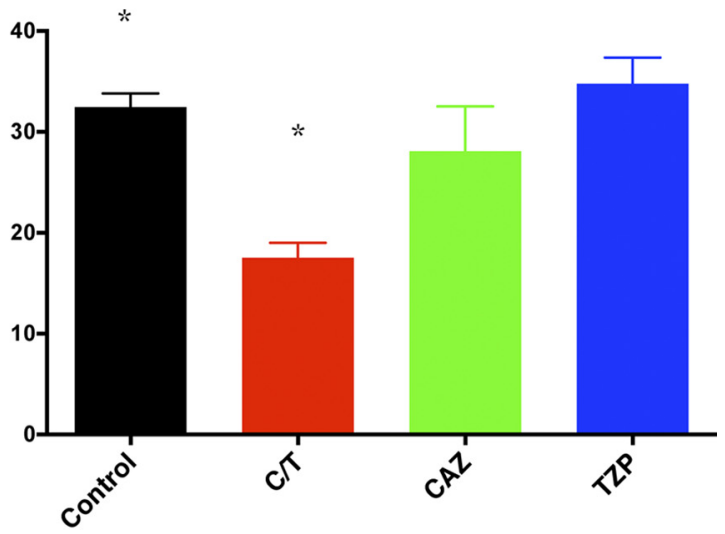

FIG 5 Lung weights (g) (marker of organism-mediated pulmonary injury) in rabbits with experimental Pseudomonas aeruginosa pneumonia treated with ceftolozane-tazobactam (C/T), ceftazidime (CAZ), and piperacillin-tazobactam (TZP) according to mechanism of resistance. ${ }^{*}, P<0.05 ; \dagger, P<0.01$ (decreased lung weights in treatment groups in comparison to that of untreated controls). All values are expressed as mean \pm SEM. The normal lung weight for the rabbits used in this study is approximately $15 \mathrm{~g}$.

methylpyridine side chain by a larger 3-amino-4-(2-aminoethylcarbamoylamino)-2methylpyrazol, which confers greater steric hindrance to $\beta$-lactamase hydrolysis. The substitution also preserves antimicrobial activity of ceftolozane against $P$. aeruginosa isolates with porin mutations. Tazobactam is a $\beta$-lactam sulfone that irreversibly binds to the active sites of class $A$ (serine) $\beta$-lactamases.

Ceftolozane-tazobactam has more potent in vitro activity against $P$. aeruginosa than traditional antipseudomonal $\beta$-lactam agents. The $\mathrm{MIC}_{90}$ for $P$. aeruginosa isolated from hospitalized patients with pneumonia is $4 / 4 \mu \mathrm{g} / \mathrm{ml}$, compared to $>32 \mu \mathrm{g} / \mathrm{ml}$ for ceftazidime, $>64 / 4 \mu \mathrm{g} / \mathrm{ml}$ for piperacillin-tazobactam, and $>8 \mu \mathrm{g} / \mathrm{ml}$ for meropenem (12). Approximately $85 \%$ of $P$. aeruginosa strains that are not susceptible to ceftazidime, piperacillin-tazobactam, and meropenem remain susceptible to ceftolozanetazobactam (13).

Surveillance data collected over 2015 to 2017 from patients hospitalized with pneumonia in the United States demonstrate that ceftolozane-tazobactam displays in vitro activity with an $\mathrm{MIC}_{90}$ of approximately $2 \mu \mathrm{g} / \mathrm{ml}$ (14). Ceftolozane-tazobactam also exerts in vitro activity of $85.7 \%$ and $90.8 \%$ against isolates of $P$. aeruginosa resistant to ceftazidime and meropenem, respectively (14).

Despite its potent in vitro activity, there are limited in vivo studies that characterize the efficacy of ceftolozane-tazobactam against Pseudomonas infections. Initial studies characterized the pharmacodynamic parameter of ceftolozane-tazobactam in the neutropenic murine thigh infection model as being $T>\operatorname{MIC}(15,16)$. 
Pan-Susceptible

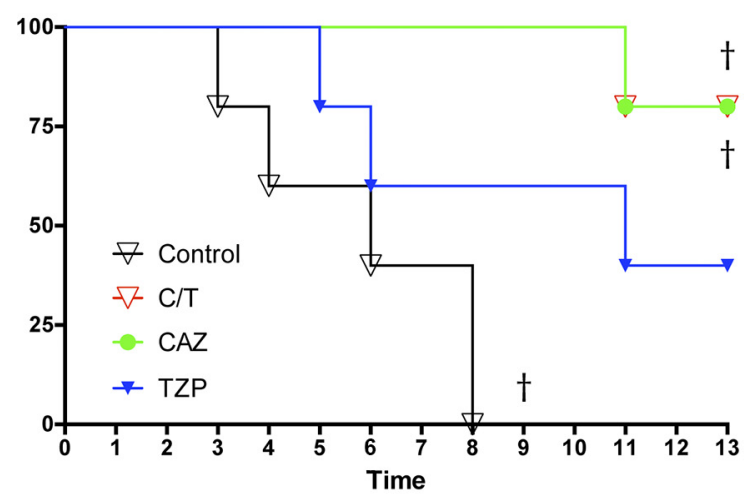

Efflux pump expression

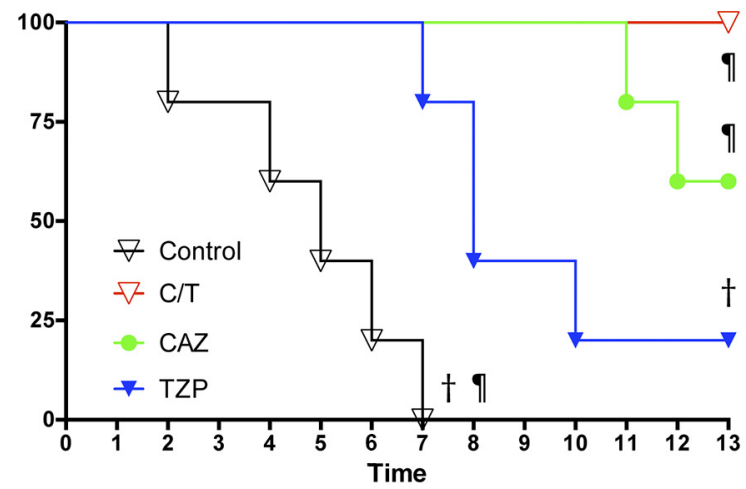

OPRD porin loss

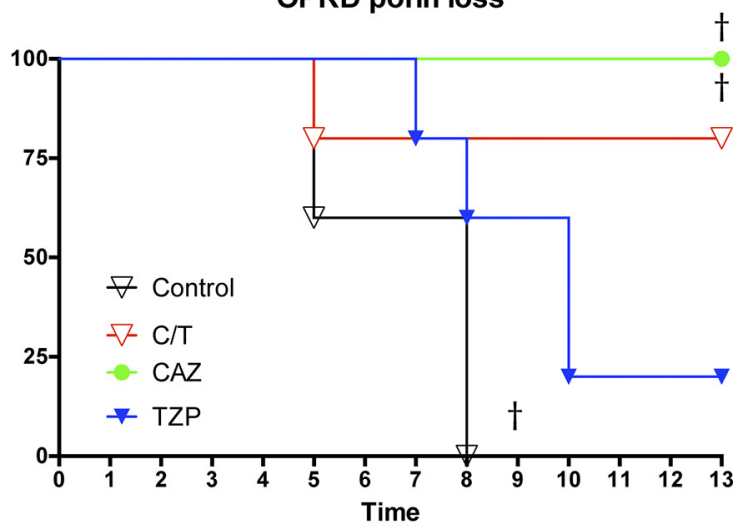

Amp C hyperexpression

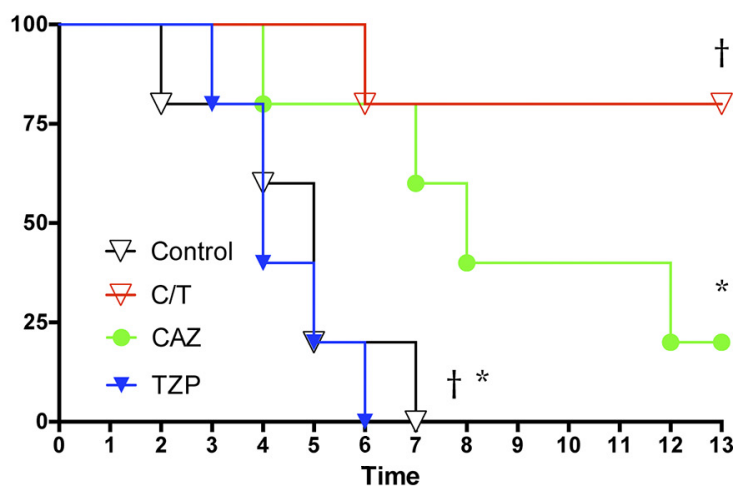

FIG 6 Cumulative survival probability in rabbits with experimental Pseudomonas aeruginosa pneumonia treated with ceftolozanetazobactam (C/T), ceftazidime (CAZ), and piperacillin-tazobactam (TZP) according to mechanism of resistance. ${ }^{*}, P<0.05 ; \dagger, P<0.01 ;$, $P<0.01$ (prolonged survival in treatment groups). All values are expressed as percentage of cumulative survival probability.

Bulik et al. demonstrated improved efficacy of ceftolozane-tazobactam in humanized dosages over piperacillin-tazobactam in an immunocompetent murine thigh model of $P$. aeruginosa infection (17). Bretonniere et al. studied the efficacy of ceftolozane alone without tazobactam in an immunocompetent rabbit model of $P$. aeruginosa pneumonia. The investigators found that ceftolozane administered at a humanized dose of $2 \mathrm{~g}$ q8h i.v. was more active than that at $1 \mathrm{~g} \mathrm{q} 8 \mathrm{~h}$ in reducing the residual bacterial burden in lung tissue (18). Our study contributes to those previous reports by utilizing a persistently neutropenic rabbit model that bears strong parallels to profoundly neutropenic patients with $P$. aeruginosa pneumonia.

The persistently neutropenic rabbit model of $P$. aeruginosa pneumonia offers important advantages in understanding pathogenesis and treatment of this lethal infection. The rabbit model reflects the human pattern of infection over a 14-day period. These models also allow for serial microbiological, pharmacokinetic, proteomic, and immunological sampling of blood over a 14-day period, thereby providing a detailed assessment of dosage, pharmacokinetic/pharmacodynamic relationships, and outcomes. These models have been applied in studies of the proteomics, pharmacokinetics and treatment of bacterial infections using ceftazidime, piperacillin-tazobactam, trimethoprim-sulfamethoxazole, ceftolozane-tazobactam, ceftazidime-avibactam, eravacycline, minocycline, polymyxin $B$, and other investigational antibacterial agents (19). The persistent neutropenia of this rabbit model also recapitulates the host deficits of immunocompromised patients with hematological malignancies, where P. aeruginosa pneumonia is an important cause of infectious mortality and morbidity.

The persistently neutropenic rabbit model of Pseudomonas pneumonia uses a minimum of four outcome variables: survival, residual bacterial burden in tissue (log 
$\mathrm{CFU} / \mathrm{g}$ ), residual bacterial burden in BAL fluid (log CFU/ml), and lung weights. While residual bacterial burden in lung tissue is a key outcome variable, characterization of bacterial burden in BAL fluid allows a parallel correlation with assessing responses of patients in clinical trials where a follow-up bronchoscopy is used for assessment of quantitative therapeutic responses in BAL fluid (20).

Assessment of lung weights provides a valuable marker of organism-mediated pulmonary injury. $P$. aeruginosa in neutropenic patients mediates pulmonary injury through a wide range of putative and proven virulence factors (21-23). The natural history of $P$. aeruginosa pneumonia in persistently neutropenic hosts is one of progressive angioinvasion, hemorrhagic infarction, edema, necrosis, and destruction of viable lung tissue. By using lung weights among the outcome variables, one can assess antimicrobial agents that may attenuate virulence, reduce organism-mediated lung injury, and decrease lung weights but without necessarily decreasing residual bacterial burden in lung tissue and BAL fluid. As reflected by this study, a rapidly microbicidal antibacterial agent should be reflected by significantly reduced mortality and residual bacterial burden in the lung tissue and BAL fluid, as well as prevention of angioinvasive lung injury, as reflected by low lung weights.

The currently approved dosage for ceftolozane-tazobactam for treatment of complicated intra-abdominal infection and complicated urinary tract infection is $1.5 \mathrm{~g}(1 \mathrm{~g}$ ceftolozane and $0.5 \mathrm{~g}$ tazobactam) q8h (9). The recently completed clinical trial of ceftolozane-tazobactam for treatment of ventilator-associated pneumonia (24) instead used a dose of $3 \mathrm{~g}$ ( $2 \mathrm{~g}$ ceftolozane and $1 \mathrm{~g}$ tazobactam) $\mathrm{q} 8 \mathrm{~h}$. The dosage used in this study of $80 \mathrm{mg} / \mathrm{kg}$ ( $53.3 \mathrm{mg} / \mathrm{kg}$ ceftolozane and $26.6 \mathrm{mg} / \mathrm{kg}$ tazobactam) i.v. q4h produced humanized plasma exposures comparable to the those achieved with a dose of $3 \mathrm{~g}$ q8h in adults. Our humanized pharmacokinetic and in vivo efficacy data provide further preclinical support for understanding the outcome of this clinical trial. For the treatment of adult patients with either ventilated hospital-acquired bacterial pneumonia (HABP) or ventilator-associated bacterial pneumonia (VABP), ceftolozane-tazobactam at $3 \mathrm{~g}$ every $8 \mathrm{~h}$ met the prespecified primary endpoints, demonstrating noninferiority to meropenem, the active comparator, in day 28 all-cause mortality and in clinical cure rate at the test of cure (25). The findings in the experiments reported here may be especially applicable to ceftolozane-tazobactam in treatment of hospital-acquired pneumonia in severely immunocompromised hosts, where there is a paucity of data. Indeed, patients were excluded from enrollment in the ventilator-associated pneumonia trial if they were actively immunosuppressed.

The optimization of ceftolozane-tazobactam to represent a humanized dose was focused on ceftolozane rather than tazobactam. Tazobactam has a minimal role in the antimicrobial activity of ceftolozane-tazobactam. While the differences in the tazobactam $\mathrm{AUC}_{8}$ suggested a faster clearance in rabbits than in humans, this difference did not appear to be statistically significant, suggesting that the time above the MIC for tazobactam would still have been sufficient to protect ceftolozane. The amount of tazobactam was sufficient to be able to significantly reduce the burden of Pseudomonas aeruginosa in rabbit lung tissue in all study groups.

This study has several limitations. The dosage of piperacillin-tazobactam was humanized for $4.5 \mathrm{~g}$ i.v. q8h. Although this is an approved dose for treating serious infections, the dose of $4.5 \mathrm{~g}$ i.v. q6h is licensed for treatment of pneumonia in immunocompromised adults. While a higher dosage may have conferred greater efficacy against the wild-type isolate, infection caused by the two isolates of Pseudomonas aeruginosa with highly elevated MICs would not have been predicted to respond to piperacillin-tazobactam. Another limitation to the study is the development of the humanized dosage of ceftolozane-tazobactam based upon the characterization and modeling in immunocompetent noninfected rabbits. However, we adapted the same strategy that had been used for development of the 3-g (2-g/1-g) dosing regimen for ceftolozane-tazobactam in humans, wherein the dosage used for treatment of pneumonia in humans was based largely upon safety/tolerability pharmacokinetic studies in normal adult volunteers. 
The results from this study establish a preclinical foundation for design and implementation of a clinical trial of ceftolozane-tazobactam as the primary treatment for $P$. aeruginosa bacteremia and pneumonia in immunocompromised patients with profound neutropenia, hematological malignancies, and/or hematopoietic stem cell transplantation. The clinical trial should be designed such that once Pseudomonas bacteremia or pneumonia was documented in this population, rather than continuing conventional agents for which there is a likelihood for emergence of resistance and failure, ceftolozane-tazobactam instead could be used as primary therapy. With the advent of rapid molecular diagnostic systems, such a strategy for early laboratory detection of $P$. aeruginosa bloodstream infection becomes even more feasible (26-28). Using ceftolozane-tazobactam for these documented $P$. aeruginosa infections could establish a paradigm shift for this new antimicrobial agent targeted specifically to Pseudomonas infection as early primary therapy guided by rapid molecular diagnostics in our most vulnerable patient population.

\section{MATERIALS AND METHODS}

Animals. Ninety-two female New Zealand White rabbits (Covance Research Products, Inc., Denver, PA) weighing 2.5 to $3.8 \mathrm{~kg}$ were used in the study. All rabbits were housed in facilities accredited by the Association for Assessment and Accreditation of Laboratory Animal Care International and according to the guidelines of the National Research Council (29) for the care and use of laboratory animals. Experiments were approved by the Weill Cornell Medicine Institutional Animal Care and Use Committee. Rabbits were individually housed and maintained with water and standard rabbit feed ad libitum.

Animal model. All rabbits had an indwelling Silastic central venous catheter that was surgically placed under general anesthesia, as previously described elsewhere (30). This enables easy atraumatic acquisition of diagnostic and pharmacokinetic samples, as well as parenteral administration of investigational antimicrobial agents and compounds required to induce and support neutropenia. Lasting 12 to 14 days in successfully treated animals, the persistently neutropenic rabbit model of $P$. aeruginosa pneumonia recapitulates the histological, radiological, and microbiological features observed in patients.

The persistently neutropenic rabbit model of Pseudomonas aeruginosa pneumonia reflects the pathogenesis and clinical course observed in persistently neutropenic patients. Colonization of the tracheobronchial mucosa is established by direct endotracheal inoculation. As the animal becomes neutropenic over a 3- to 7-day (median, 5 days) course of time, the tracheobronchial colonization progresses to multilobar pneumonia. As the pneumonia progresses over the course of 5 to 7 days in untreated control animals, five or six lobes, including the lingua, become infected. The infection is characterized histologically by angioinvasion, hemorrhagic infarction, and focal parenchymal hemorrhage, in a histologic pattern that recapitulates the infection observed in neutropenic patients. The lung weights, which are normally a median of $15 \mathrm{~g}$ in normal rabbits, increase progressively over the course of 7 days in the neutropenic rabbit model of Pseudomonas aeruginosa pneumonia to a median of $30 \mathrm{~g}$. The increasing weight is directly related to the organism-mediated pulmonary injury that develops progressively in the untreated host. The primary cause of death in this persistently neutropenic rabbit model of Pseudomonas aeruginosa pneumonia is progressive respiratory failure. However, using humane endpoints, the animals are euthanized before respiratory failure or clinically significant respiratory distress develops. The model permits a robust range of outcome variables, including residual bacterial burden (log CFU/g), lung weights (a measure of organism-mediated pulmonary injury), and survival. Rabbits receive antimicrobial therapy for as long terminal repeat as 12 days. Similar to those of patients, the length of survival and duration of therapy permit assessment of the emergence of resistance to antimicrobial agents.

Antibacterial drugs and treatment groups. Commercially available ceftolozane-tazobactam (Zerbaxa, Merck \& Co., Inc., Whitehouse Station, NJ), ceftazidime (GlaxoSmithKline, Research Triangle, NC), and piperacillin-tazobactam (AuroMedics Pharma LLC, E. Windsor, NJ) were used during all experiments. Ceftazidime and piperacillin-tazobactam were used as treatment controls against four isolates of $P$. aeruginosa. Study drugs were prepared in accordance with the manufacturers' instructions. The dosing regimen was selected to match the free drug time above the MIC and plasma AUC achieved in humans with the following dosages: ceftolozane-tazobactam, $3 \mathrm{~g}(2 \mathrm{~g} / 1 \mathrm{~g})$ q8h; CAZ, $2 \mathrm{~g}$ q8h; and TZP, $4.5 \mathrm{~g}$ q8h. The humanized dosing regimens used in rabbits were ceftolozane-tazobactam (C/T) at $80 \mathrm{mg} / \mathrm{kg}$ q $4 \mathrm{~h}$ i.v., ceftazidime (CAZ) at $80 \mathrm{mg} / \mathrm{kg}$ q4h i.v., and piperacillin-tazobactam (TZP) at $80 \mathrm{mg} / \mathrm{kg}$ q4h i.v., along with untreated controls (UC). Piperacillin-tazobactam (TZP) at $4.5 \mathrm{~g}$ i.v. q8h and ceftazidime (CAZ) at $2 \mathrm{~g}$ i.v. q8h, which served as control treatments, were administered in humanized dosages $(18,31-35)$. Adjustments in dosing intervals were required because of the more rapid elimination of ceftolozane $(0.75 \mathrm{~h}$ versus $2.5 \mathrm{~h}$ ), CAZ ( $4 \mathrm{~h}$ versus $8 \mathrm{~h}$ ), and TZP ( $4 \mathrm{~h}$ versus $8 \mathrm{~h}$ ) in rabbits than in humans. Treatment was continued for 12 days in surviving animals. TZP and CAZ were used in these experiments as negative controls for treatment of molecularly defined resistant strains of $P$. aeruginosa such that a lack of response in vivo would be predicted. The efficacy of $C / T$ was not compared directly to that of TZP or CAZ.

Multidose plasma pharmacokinetics. The plasma pharmacokinetics of ceftolozane-tazobactam were determined to identify the dosage in rabbits that would achieve exposure comparable to that of $3 \mathrm{~g}$ ( $2 \mathrm{~g}$ ceftolozane/1 $\mathrm{g}$ tazobactam) i.v. $\mathrm{q} 8 \mathrm{~h}$ in humans. 
TABLE 2 MICs of ceftolozane-tazobactam, ceftazidime, and piperacillin-tazobactam against the Pseudomonas aeruginosa isolates used in the study

\begin{tabular}{llll}
\hline & MIC $(\boldsymbol{\mu g} / \mathrm{ml})$ & & Piperacillin- \\
\cline { 2 - 4 } Isolate, mechanism of resistance & $\begin{array}{l}\text { Ceftolozane- } \\
\text { tazobactam }\end{array}$ & Ceftazidime & $\begin{array}{l}\text { tazobactam } \\
\text { tazim }\end{array}$ \\
\hline PAE 3656, pan-susceptible & 0.5 & 8 & 8 \\
PAE 3616, OPRD porin loss & 2 & 16 & 16 \\
PAE 3647, efflux pump expression & 4 & $>32$ & $>64$ \\
PAE 3691, AmpC hyperexpression & 2 & 32 & $>64$ \\
\hline
\end{tabular}

Three cohorts of four animals per group received ceftolozane-tazobactam at $40 \mathrm{mg} / \mathrm{kg}, 80 \mathrm{mg} / \mathrm{kg}$, or $160 \mathrm{mg} / \mathrm{kg}$ as an i.v. infusion every $8 \mathrm{~h}$, with serial plasma sampling on day 6 of multidosing. Blood samples $(1.0 \mathrm{ml})$ were drawn before administration of ceftolozane-tazobactam and then at $0.5,1,2,4,6$, and $8 \mathrm{~h}$ after the start of the i.v. infusion. Blood samples were collected in heparinized syringes, and plasma was separated by centrifugation. All plasma and epithelial lining fluid (ELF) samples were stored at $-80^{\circ} \mathrm{C}$ until assayed. Ceftolozane-tazobactam levels in plasma and ELF were determined by highpressure liquid chromatography (HPLC) assay and UV detection, as described by Sutherland and Nicolau (36). The pharmacokinetic profiles for ceftolozane and tazobactam were computed from the drug concentration-time data using noncompartmental methods.

Induction and maintenance of neutropenia. Profound and persistent neutropenia $(<100 / \mu l$ neutrophils) was induced 1 day before the endotracheal inoculation of the animals and maintained by cytarabine (Ara-C) at $525 \mathrm{mg} / \mathrm{m}^{2}$ i.v. for 5 consecutive days. During the study, Ara-C at $484 \mathrm{mg} / \mathrm{m}^{2}$ i.v. was administered on days 8 to 9 and 13 to 14 of the experiment to maintain persistent neutropenia. Additional immunosuppression was induced with methylprednisolone. Methylprednisolone at $5 \mathrm{mg} / \mathrm{kg}$ of body weight was administered on days 1 and 2 of the experiment to inhibit macrophage activity and to facilitate establishment of infection. Vancomycin ( $15 \mathrm{mg} / \mathrm{kg}$ given intravenously) was administered daily from day 4 of chemotherapy until study completion for prevention of opportunistic Gram-positive bacterial infections. Vancomycin was administered orally in drinking water at $50 \mathrm{mg} / \mathrm{liter}$ in order to prevent the development of diarrhea caused by Clostridium spiroforme.

White blood cell counts (total leukocyte counts) and the percentages of neutrophils were monitored twice weekly with a Coulter Counter and by peripheral blood smears and differential counts, respectively.

Organisms and inoculation. Four isolates of $P$. aeruginosa, from the classification groups pansusceptible (PS), OPRD porin loss (OPRDPL), efflux pump expression (EPE), and AmpC hyperexpression (ACHE), were studied. The MICs for the four clinical isolates of $P$. aeruginosa that were studied in the rabbit model are summarized in Table 2. All isolates were susceptible to ceftolozane-tazobactam but not to comparators, which were used as negative treatment controls. Further details of the molecular characterization of the resistance mechanisms of the $P$. aeruginosa isolates were described by Castanheira et al. (37).

Pseudomonas pneumonia was established by direct endotracheal inoculation to achieve tracheobronchial colonization that evolves into bronchopneumonia in persistently neutropenic rabbits. The concentration was adjusted to give each rabbit a predetermined inoculum of $1.0 \times 10^{8}$ organisms in a volume of 250 to $350 \mu \mathrm{l}$. Inoculation with $P$. aeruginosa was performed on experiment day 2, while rabbits were under general anesthesia $(0.5$ to $0.6 \mathrm{ml}$ of a $2: 1$ [vol/vol] mixture of ketamine $[100 \mathrm{mg} / \mathrm{ml}]$ and xylazine $[20 \mathrm{mg} / \mathrm{ml}]$ administered intravenously).

Once satisfactory anesthesia was obtained, a Flagg O straight-blade laryngoscope (Welch-Allyn Inc., Skaneateles Falls, NY) was inserted into the oral cavity until the vocal cords were clearly visible. The inoculum was then administered intratracheally with a tuberculin syringe attached to a 5.25-in. 16-gauge Teflon catheter (Becton, Dickinson Infusion Therapy Systems Inc., Sandy, UT).

Established P. aeruginosa pneumonia is presented in Fig. 7 Hematoxylin and eosin (Fig. 7, upper panel) and tissue Gram (Fig. 7, lower panel) stains of $P$. aeruginosa-infected neutropenic rabbit lung tissue in rabbits with experimental $P$. aeruginosa pneumonia revealed severe, multifocal to coalescing, subacute, necrotizing pneumonia (upper panel) with thrombosis, pleuritis, marked edema, hemorrhage, and large numbers of intra- and extracellular Gram-negative bacilli within most lesions (lower panel).

Outcome variables. The therapeutic response was assessed by residual bacterial burden (quantitative cultures from lung tissue [log CFU/g] and quantitative cultures of bronchoalveolar lavage [BAL] fluid [log $\mathrm{CFU} / \mathrm{ml}]$ ), lung weights (g), and cumulative survival probability (\%).

(i) Quantitative cultures of lung tissue. Lung tissues from each rabbit were sampled and cultured by standard excision of tissue from each lobe. Each tissue sample was weighed, placed in a sterile polyethylene bag (Tekmar Corp., Cincinnati, OH), and homogenized with sterile saline for $30 \mathrm{~s}$ (Stomacher 80; Tekmar Corp., Cincinnati, OH). Lung homogenate dilutions $\left(10^{-1}\right.$ and $\left.10^{-2}\right)$ were prepared in sterile $0.9 \%$ normal saline (NS). Aliquots of $100 \mu \mathrm{l}$ from homogenates and homogenate dilutions were plated on Mueller-Hinton agar plates, incubated at $37^{\circ} \mathrm{C}$ for the first $24 \mathrm{~h}$, and then left at room temperature for another $24 \mathrm{~h}$. Carryover of the drug was controlled by serial dilution and by streaking of a small aliquot $(100 \mu \mathrm{l})$ onto a large volume of agar (one full agar plate per 100- $\mu \mathrm{l}$ aliquot). The number of CFU of $P$. aeruginosa was counted and recorded for each lobe, and the CFU per gram was calculated. A finding of one colony of $P$. aeruginosa was considered positive.

(ii) Quantitative cultures of BAL fluid. Bronchoalveolar lavage was performed on each postmortemexcised tracheobronchial tree and lung preparation. An aliquot of $10 \mathrm{ml}$ of sterile $0.9 \%$ normal saline was 


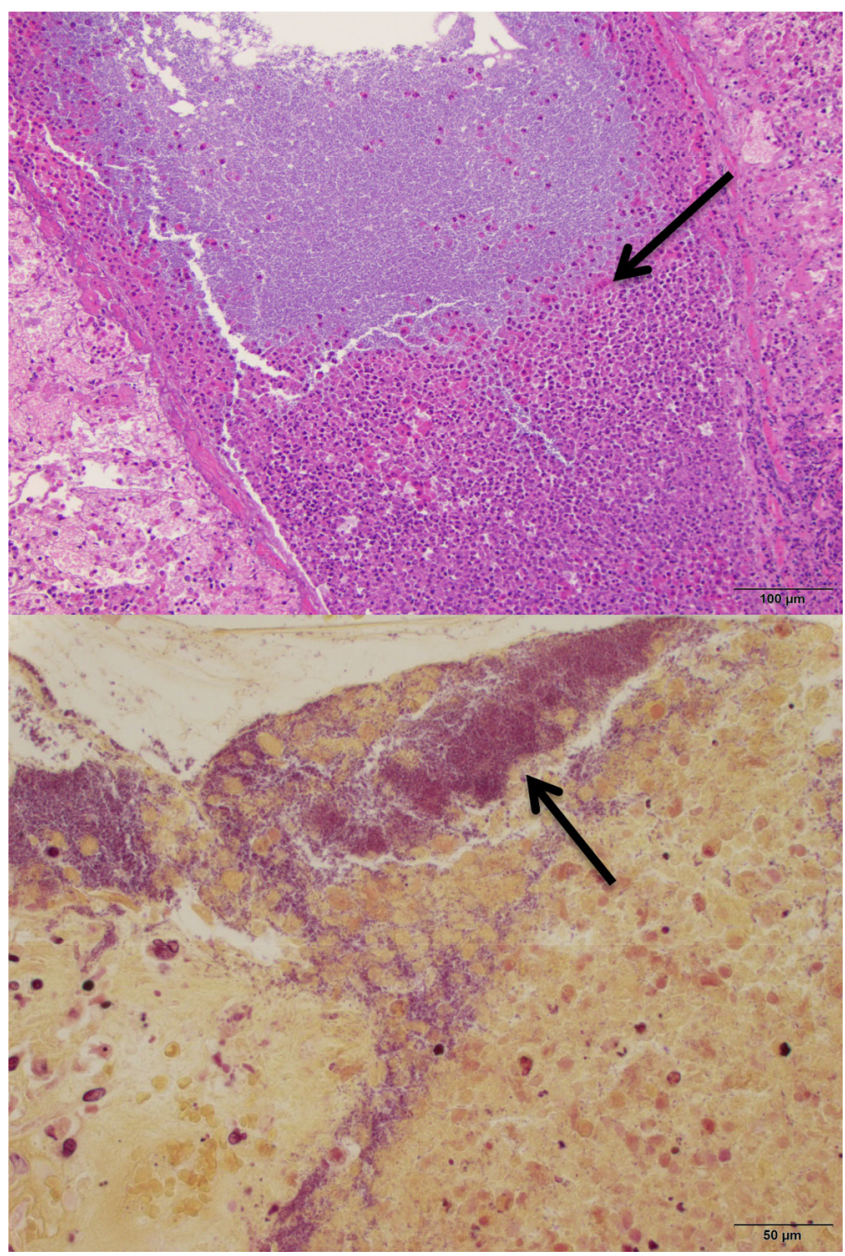

FIG 7 Hematoxylin and eosin (upper panel) and tissue Gram (lower panel) stains of $P$. aeruginosa-infected neutropenic rabbit lung tissue in a rabbit with experimental Pseudomonas aeruginosa pneumonia, showing severe, multifocal to coalescing, subacute, necrotizing pneumonia (upper panel) with thrombosis, pleuritis, marked edema, hemorrhage, and intralesional Gram-negative bacilli (lower panel). Large numbers of intra- and extracellular Gram-negative bacilli are present within most lesions (lower panel).

instilled and subsequently withdrawn from the clamped trachea with a sterile 12-ml syringe. The process was repeated for a total infusion of $20 \mathrm{ml}$. The lavaged fluid $(8$ to $15 \mathrm{ml})$ was centrifuged for $10 \mathrm{~min}$ at $400 \times g$. The supernatant was then removed, leaving $2.0 \mathrm{ml}$ of pellet. The pellet was vortexed, and dilutions $\left(10^{-1}\right.$ and $\left.10^{-2}\right)$ were prepared in sterile NS. Aliquots of $100 \mu \mathrm{l}$ from the pellet and pellet dilutions were plated on Mueller-Hinton agar plates, incubated at $37^{\circ} \mathrm{C}$ for the first $24 \mathrm{~h}$, and then left at room temperature for another $24 \mathrm{~h}$. The number of CFU of $P$. aeruginosa was counted and recorded for each rabbit, and the CFU per $\mathrm{ml}$ was calculated.

(iii) Lung weights. The total lung weights are markers of organism-mediated tissue injury. The entire heart-lung block was carefully resected at autopsy. The heart was dissected away from the lungs, leaving the tracheobronchial tree and lungs intact. The lungs were weighed and inspected by at least two observers, who were unaware of the treatment group. The average of the total lung weight was calculated for each study group.

(iv) Survival. Survival time in days postinoculation was recorded for each rabbit in each group. Rabbits were euthanized according to Animal Care and Use Committee-approved prespecified humane endpoints by i.v. administration of pentobarbital ( $65 \mathrm{mg}$ of pentobarbital sodium $/ \mathrm{kg}$ of body weight) (SomnaSol Euthanasia-III Solution C3N; Henry Schein Animal Health, Dublin, OH). Surviving rabbits were euthanatized on day 13 postinoculation, $24 \mathrm{~h}$ after the last dose of the study drug.

Statistical analysis. The central hypothesis of the study was that ceftolozane-tazobactam was active in vivo in treatment of wild-type susceptible and molecularly defined resistant strains of $P$. aeruginosa in the persistently neutropenic rabbit model of Pseudomonas pneumonia. As TZP and CAZ were used in these experiments as negative controls for treatment of molecularly defined resistant strains of $P$. aeruginosa, the in vivo efficacy of $\mathrm{C} / \mathrm{T}$ in this model was not compared directly to that of TZP or CAZ. Comparisons between the groups were performed by the Kruskal-Wallis test (nonparametric analysis of variance [ANOVA]) or the Mann-Whitney $U$ test, as appropriate. A two-tailed $P$ value of $\leq 0.05$ was considered to be statistically significant. Survival was plotted by Kaplan-Meier analysis. Differences in 
survival of treatment groups and untreated controls were analyzed by the log rank test. Values are expressed as means \pm standard errors of the means (SEMs). Correlation between dosage of ceftolozanetazobactam and AUC was determined by Pearson's correlation coefficient.

\section{ACKNOWLEDGMENTS}

This study was supported in part by an unrestricted research grant from Merck to Weill Cornell Medicine.

T.J.W. has received grants for experimental and clinical antimicrobial pharmacology and therapeutics to his institution from Merck and has served as consultant to Merck. A.C.D. and D.L.C. are employees of Merck. D.P.N. is a consultant and member of the speakers' bureau for Merck \& Co., Inc.

\section{REFERENCES}

1. Perez F, Adachi J, Bonomo RA. 2014. Antibiotic-resistant gram-negative bacterial infections in patients with cancer. Clin Infect Dis 59(Suppl 5):S335-S339. https://doi.org/10.1093/cid/ciu612.

2. Rolston KV. 2017. Infections in cancer patients with solid tumors: a review. Infect Dis Ther 6:69-83. https://doi.org/10.1007/s40121-017 -0146-1.

3. Satlin MJ, Walsh TJ. 2017. Multidrug-resistant Enterobacteriaceae, Pseudomonas aeruginosa, and vancomycin-resistant Enterococcus: three major threats to hematopoietic stem cell transplant recipients. Transpl Infect Dis 19:e12762. https://doi.org/10.1111/tid.12762.

4. van Duin D, Bonomo RA. 2016. Ceftazidime/avibactam and ceftolozane/ tazobactam: second-generation beta-lactam/beta-lactamase inhibitor combinations. Clin Infect Dis 63:234-241. https://doi.org/10.1093/cid/ ciw243.

5. Monogue ML, Nicolau DP. 2018. Antibacterial activity of ceftolozane/ tazobactam alone and in combination with other antimicrobial agents against MDR Pseudomonas aeruginosa. J Antimicrob Chemother 73: 942-952. https://doi.org/10.1093/jac/dkx483.

6. See I, Freifeld AG, Magill SS. 2016. Causative organisms and associated antimicrobial resistance in healthcare-associated, central line-associated bloodstream infections from oncology settings, 2009-2012. Clin Infect Dis 62:1203-1209. https://doi.org/10.1093/cid/ciw113.

7. Hakki M, Lewis JS, II. 2018. Ceftolozane-tazobactam therapy for multidrug-resistant Pseudomonas aeruginosa infections in patients with hematologic malignancies and hematopoietic-cell transplant recipients. Infection 46:431-434. https://doi.org/10.1007/s15010-018-1125-5.

8. Yu B, Adedoyin A, Hershberger E, Caro L, Xiao A, Rhee EG, Huntington JA. 2018. Safety, tolerability, and pharmacokinetics of $3 \mathrm{~g}$ of ceftolozane/ tazobactam in healthy adults: a randomized, placebo-controlled, multipledose study. Clin Pharmacol Drug Dev 7:382-391. https://doi.org/10.1002/ cpdd.429.

9. FDA. 2014. ZERBAXA (ceftolozane/tazobactam) label-FDA. https://www .accessdata.fda.gov/drugsatfda_docs/label/2014/206829lbl.pdf.

10. Kollef M, Nováček M, Kivistik Ü, Réa-Neto Á, Shime N, Martin-Loeches I, Timsit J-F, Wunderink RG, Bruno CJ, Huntington JA, Lin CY, Yu B, Butterton JR, Rhee EG. 2019. ASPECT-NP: a randomized, double-blind, phase III trial comparing efficacy and safety of ceftolozane/tazobactam versus meropenem in patients with ventilated nosocomial pneumonia (VNP), poster P1917. Abstr Eur Clin Congr Microbiol Infect Dis, Amsterdam, Netherlands.

11. Bassetti M, Vena A, Castaldo N, Righi E, Peghin M. 2018. New antibiotics for ventilator-associated pneumonia. Curr Opin Infect Dis 31:177-186. https://doi.org/10.1097/QCO.0000000000000438.

12. Farrell DJ, Sader HS, Flamm RK, Jones RN. 2014. Ceftolozane/tazobactam activity tested against Gram-negative bacterial isolates from hospitalised patients with pneumonia in US and European medical centres (2012). Int J Antimicrob Agents 43:533-539. https://doi.org/10.1016/j.ijantimicag 2014.01.032.

13. Farrell DJ, Flamm RK, Sader HS, Jones RN. 2013. Antimicrobial activity of ceftolozane-tazobactam tested against Enterobacteriaceae and Pseudomonas aeruginosa with various resistance patterns isolated in U.S. hospitals (2011-2012). Antimicrob Agents Chemother 57:6305-6310. https://doi.org/10.1128/AAC.01802-13.

14. Carvalhaes CG, Castanheira M, Sader HS, Flamm RK, Shortridge D. 2018. Antimicrobial activity of ceftolozane-tazobactam tested against gramnegative contemporary (2015-2017) isolates from hospitalized patients with pneumonia in US medical centers. Diagn Microbiol Infect Dis https://doi.org/10.1016/j.diagmicrobio.2018.11.021

15. Craig WA, Andes DR. 2013. In vivo activities of ceftolozane, a new cephalosporin, with and without tazobactam against Pseudomonas aeruginosa and Enterobacteriaceae, including strains with extendedspectrum beta-lactamases, in the thighs of neutropenic mice. Antimicrob Agents Chemother 57:1577-1582. https://doi.org/10.1128/AAC.01590-12.

16. Lepak AJ, Reda A, Marchillo K, Van Hecker J, Craig WA, Andes D. 2014. Impact of MIC range for Pseudomonas aeruginosa and Streptococcus pneumoniae on the ceftolozane in vivo pharmacokinetic/pharmacodynamic target. Antimicrob Agents Chemother 58:6311-6314. https://doi.org/10 .1128/AAC.03572-14.

17. Bulik CC, Tessier PR, Keel RA, Sutherland CA, Nicolau DP. 2012. In vivo comparison of CXA-101 (FR264205) with and without tazobactam versus piperacillin-tazobactam using human simulated exposures against phenotypically diverse gram-negative organisms. Antimicrob Agents Chemother 56:544-549. https://doi.org/10.1128/AAC.01752-10.

18. Bretonniere C, Boutoille D, Caillon J, Desessard C, Guitton C, Potel G, Jacqueline C. 2014. In vivo efficacy of ceftolozane against Pseudomonas aeruginosa in a rabbit experimental model of pneumonia: comparison with ceftazidime, piperacillin/tazobactam and imipenem. Int J Antimicrob Agents 44:218-221. https://doi.org/10.1016/j.ijantimicag.2014.04 017 .

19. Gonzales DA, De Torre C, Wang H, Devor CB, Munson PJ, Ying SX, Kern SJ, Petraitiene R, Levens DL, Walsh TJ, Suffredini AF. 2010. Protein expression profiles distinguish between experimental invasive pulmonary aspergillosis and Pseudomonas pneumonia. Proteomics 10:4270-4280. https://doi.org/ 10.1002/pmic.200900768.

20. Drusano GL, Corrado ML, Girardi G, Ellis-Grosse EJ, Wunderink RG, Donnelly $H$, Leeper KV, Brown $M$, Malek $T$, Hite RD, Ferrari $M$, Djureinovic $D$, Kollef MH, Mayfield L, Doyle A, Chastre J, Combes A, Walsh TJ, Dorizas K, Alnuaimat $\mathrm{H}$, Morgan BE, Rello J, Mazo CA, Jones RN, Flamm RK, Woosley L, Ambrose PG, Bhavnani S, Rubino CM, Bulik CC, Louie A, Vicchiarelli M, Berman C. 2018. Dilution factor of quantitative bacterial cultures obtained by bronchoalveolar lavage in patients with ventilator-associated bacterial pneumonia. Antimicrob Agents Chemother 62:e01323-17. https://doi.org/10.1128/AAC.01323-17.

21. Cezard C, Farvacques N, Sonnet P. 2015. Chemistry and biology of pyoverdines, Pseudomonas primary siderophores. Curr Med Chem 22: 165-186.

22. Gellatly SL, Hancock RE. 2013. Pseudomonas aeruginosa: new insights into pathogenesis and host defenses. Pathog Dis 67:159-173. https:// doi.org/10.1111/2049-632X.12033.

23. Oliver A, Mulet X, López-Causapé C, Juan C. 2015. The increasing threat of Pseudomonas aeruginosa high-risk clones. Drug Resist Updat 21-22: 41-59. https://doi.org/10.1016/j.drup.2015.08.002.

24. U.S. National Library of Medicine. 2018. Safety and efficacy study of ceftolozane/tazobactam to treat ventilated nosocomial pneumonia (MK7625A-008) (ASPECT-NP). https://clinicaltrials.gov/ct2/show/NCT02070757.

25. Merck. 2018. Merck's ZERBAXA (ceftolozane and tazobactam) met primary endpoints of non-inferiority compared to meropenem in pivotal phase 3 study of adult patients with hospital-acquired bacterial pneumonia or ventilator-associated bacterial pneumonia. Merck, Kenilworth, NJ.

26. Banerjee R, Teng CB, Cunningham SA, Ihde SM, Steckelberg JM, Moriarty JP, Shah ND, Mandrekar JN, Patel R. 2015. Randomized trial of rapid multiplex polymerase chain reaction-based blood culture identification 
and susceptibility testing. Clin Infect Dis 61:1071-1080. https://doi.org/ 10.1093/cid/civ447.

27. Clancy CJ, Nguyen MH. 2018. T2 magnetic resonance for the diagnosis of bloodstream infections: charting a path forward. J Antimicrob Chemother 73:iv2-iv5. https://doi.org/10.1093/jac/dky050.

28. Leber AL, Everhart K, Daly JA, Hopper A, Harrington A, Schreckenberger P, McKinley K, Jones M, Holmberg K, Kensinger B. 2018. Multicenter evaluation of BioFire FilmArray Respiratory Panel 2 for detection of viruses and bacteria in nasopharyngeal swab samples. J Clin Microbiol 56:e01945-17. https://doi.org/10.1128/JCM.01945-17.

29. National Research Council. 2011. Guide for the care and use of laboratory animals, 8th ed. National Academies Press, Washington, DC.

30. Walsh TJ, Bacher J, Pizzo PA. 1988. Chronic silastic central venous catheterization for induction, maintenance and support of persistent granulocytopenia in rabbits. Lab Anim Sci 38:467-471.

31. Acred P. 1983. Therapeutic and kinetic properties of ceftazidime in animals. Infection 11(Suppl 1):S44-S48. https://doi.org/10.1007/BF01641106.

32. Boutoille D, Jacqueline C, Le Mabecque V, Potel G, Caillon J. 2009. In vivo impact of the MexAB-OprM efflux system on beta-lactam efficacy in an experimental model of Pseudomonas aeruginosa infection. Int J Antimicrob Agents 33:417-420. https://doi.org/10.1016/j.ijantimicag.2008.10 .029 .
33. Kern W, Kennedy SL, Sachdeva M, Sande ER, Gunderson D, Tauber MG. 1990. Evaluation of piperacillin-tazobactam in experimental meningitis caused by a beta-lactamase-producing strain of K1-positive Escherichia coli. Antimicrob Agents Chemother 34:697-701. https://doi.org/10.1128/ aac.34.5.697.

34. McColm AA, Ryan DM. 1986. Penetration of ceftazidime into the rabbit respiratory tract. J Antimicrob Chemother 18:593-597. https://doi.org/ 10.1093/jac/18.5.593.

35. Sakata Y, Boccazzi A, McCracken GH, Jr. 1983. Pharmacokinetics and bacteriological effect of ceftazidime in experimental Streptococcus pneumoniae, Haemophilus influenzae, and Escherichia coli meningitis. Antimicrob Agents Chemother 23:213-217. https://doi.org/10.1128/AAC .23.2.213.

36. Sutherland CA, Nicolau DP. 2016. Development of an HPLC method for the determination of ceftolozane/tazobactam in biological and aqueous matrixes. J Chromatogr Sci 54:1037-1040. https://doi.org/10 .1093/chromsci/bmw047.

37. Castanheira M, Mills JC, Farrell DJ, Jones RN. 2014. Mutation-driven beta-lactam resistance mechanisms among contemporary ceftazidimenonsusceptible Pseudomonas aeruginosa isolates from U.S. hospitals. Antimicrob Agents Chemother 58:6844-6850. https://doi.org/10.1128/ AAC.03681-14. 